\title{
Article
}

\section{Gender and Vulnerable Populations in Benefit Sharing: An Exploration of Conceptual and Contextual Points}

Alverez-Castillo, Fatima, Cook Lucas, Julie and Cordillera Castillo, Rosa

Available at http://clok.uclan.ac.uk/16030/

Alverez-Castillo, Fatima, Cook Lucas, Julie ORCID: 0000-0002-6391-5430 and Cordillera Castillo, Rosa (2009) Gender and Vulnerable Populations in Benefit Sharing: An Exploration of Conceptual and Contextual Points. Cambridge Quarterly of Healthcare Ethics, 18 (02). p. 130. ISSN 0963-1801

It is advisable to refer to the publisher's version if you intend to cite from the work. http://dx.doi.org/10.1017/S0963180109090227

For more information about UCLan's research in this area go to http://www.uclan.ac.uk/researchgroups/ and search for <name of research Group>.

For information about Research generally at UCLan please go to http://www.uclan.ac.uk/research/

All outputs in CLoK are protected by Intellectual Property Rights law, including Copyright law. Copyright, IPR and Moral Rights for the works on this site are retained by the individual authors and/or other copyright owners. Terms and conditions for use of this material are defined in the policies page.

\section{CLoK}

Central Lancashire online Knowledge www.clok.uclan.ac.uk

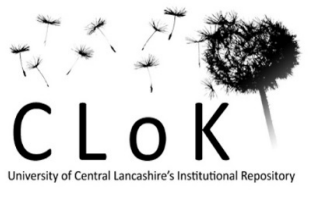




\section{Gender and Vulnerable Populations in Benefit Sharing: An Exploration of Conceptual and Contextual Points}

FATIMA ALVAREZ-CASTILLO, JULIE COOK LUCAS, and ROSA CORDILLERA CASTILLO

Vulnerable populations have been defined as those who face a significant probability of incurring an identifiable harm while substantially lacking ability and/or means to protect themselves. ${ }^{1}$ Vulnerabilities within population groups can be differentiated by factors that determine the different probabilities of incurring identifiable harms (risks) people face and the means available to them to protect themselves (their protective capacity). Among these factors is gender.

From a gender perspective, vulnerability is the probability of incurring harm, while lacking the ability and/or means for protection as a result of gendered inequalities, which in turn differentiate vulnerabilities among individuals and groups. A gender analysis thus avoids the problem of "false categorizations" posed by Schroeder and Gefenas by specifying the vulnerabilities of individuals and groups in the context of gendered relations.

Gender refers to the socially constructed identities, roles, and status that influence the allocation of power, entitlements, opportunities, and prestige to men and women. Gender inequity results from the maldistribution of resources, opportunities, and power based on gender. In all societies in the world, gender inequity mostly victimizes women. ${ }^{2}$

Vulnerability is complex and fluid. It is complex because it is the result of interacting factors and situations. For example, in Africa, poverty, gender, working in the informal economy, and behavioral and social relationship factors correlate in influencing women's susceptibility to HIV infection. ${ }^{3}$ Vulnerability is fluid because it is not the inevitable consequence of biological circumstances but of power relations that are embedded in relationships, norms, practices, and policies. This implies that risks could be minimized and protective capacity enhanced with changes in power relations.

Since 1992 the Convention on Biological Diversity has required the fair and equitable sharing of benefits arising from the use of plant genetic resources. ${ }^{4}$ However, it has been argued that such "vague and general statements," together with similar recommendations in international guidelines on research ethics, such as the UNESCO Declaration and the HUGO Statement, "can have the objective effect of covering up inequities that already exist, or even of worsening them." ${ }^{5}$

This paper was prepared for GenBenefit, a research project funded by the European Community's Sixth Framework Programme, but reflects only the authors' views. We are grateful to all the members of the wider GenBenefit group for input into this discussion. The comments of Doris Schroeder on the drafts are gratefully acknowledged. 
Although there are variations between benefit sharing cases reported in this issue on the question of women's vulnerability, a common theme has emerged from our own research that there is a risk of women being underrepresented or their needs overlooked in benefit sharing negotiations and arrangements. ${ }^{6}$

This paper discusses gender-based vulnerability in a benefit sharing context. The first section explains how gender determines vulnerability. The succeeding section takes up the layered, multidimensional, and dynamic nature of women's vulnerabilities. We argue that where vulnerable populations are at risk from exploitation through involvement in medical research, this should act as a marker to indicate that "benefit sharing arrangements must explicitly protect women's rights to a just share as well as their autonomy over the use of benefits." ${ }^{7} \mathrm{We}$ conclude that in addition to the formulation of guidelines for fair benefit sharing, women's protective capacity against exploitation in benefit sharing for medical research should also be improved. We end with recommendations for how this might be approached.

\section{Increased Vulnerability as a Consequence of Gender Inequality}

Gender-based vulnerabilities exist in almost all societies in the world, resulting from deprivation, discrimination, and oppression due to norms, practices, institutions, and policies that encourage or tolerate or ignore differences in status, privileges, rights, and opportunities between men and women. This is seen in some contemporary societies where women are deprived of education, the right to own property, and the right to political participation. ${ }^{8}$

It is well established that specific gender constructions are linked with different risks to men and women. For example, men are at greater risk of being victims of homicide and women are at greater risk of violence from their intimate partners (e.g., domestic and sexual abuse). ${ }^{9}$

Statistics on HIV/AIDS in Africa are particularly instructive on gender differentiated vulnerabilities. In 1985, only $35 \%$ of the HIV+ population were women. By 2004 , almost $50 \%$ were women, $67 \%$ of whom were aged $15-24 .{ }^{10}$ Women's greatest risk of infection is from their male partners. ${ }^{11}$

Gender is also a factor that differentiates people's protective capacities. For example, the public health strategy of promoting condom use to prevent HIV transmission could fail to protect women if undertaken without recognizing the power differential in heterosexual relationships, where women have less power than men. ${ }^{12}$ Women may fear asking their partner to wear a condom as this may be seen as admitting adultery, or accusing her partner of such, and could result in violence and forced intercourse. ${ }^{13}$

Both inside and outside of commercial sexual transactions, it is men who generally decide whether or not to use a condom; women oftentimes give in to the sexual demands of their partner. Additionally, as men may pay more for sex without a condom, sex workers may have a financial interest in taking this risk, thus further compounding the relationship between their poverty and their vulnerability to HIV infection. ${ }^{14}$

These examples indicate some of the ways in which gender inequity severely compromises poor women's capacity to protect themselves. Any discussion of risk and protective capacity must be contextualized in the power relations that exist not only between the rich and the poor but also between men and women. 


\section{Gender-Based Vulnerability in Indigenous Societies}

In the context of benefit sharing agreements in developing countries, indigenous peoples are frequently involved in issues around the use of traditional knowledge and access to plant and animal genetic resources.

Some indigenous communities are egalitarian; but others are patriarchal. ${ }^{15}$ All of these communities are under threat, but those that are thought to have once been egalitarian ${ }^{16}$ are specifically undermined by the inroads of colonization, the cash economy, and the consequent changes in division of labor and social relations. Restructuring of gender roles in formerly egalitarian indigenous societies occurs primarily because of indigenous groups' (often unwilling) engagement with the dominant society. ${ }^{17}$

Heike Becker reveals the details of one such historical story. She argues that the increased violence she documents "between San men and women has been reproduced and exacerbated by San re-appropriation of gender as a significant social category." ${ }^{18}$ Before increased interaction with the dominant society, the San in the Kalahari (Botswana) are believed to have been much more egalitarian societies than we see today. Both men and women's contribution to the group's economic resources were valued equally. Like the men, women had substantial authority in decisionmaking both in the household and in the group. ${ }^{19}$

Social changes that occurred when they were incorporated into the capitalist economy were experienced differently by men and women, which has impacted their protective capacity. "The process through which men gained control over material and immaterial resources, enhancing their influence and power within their communities, were matched by women's loss of resources, power and influence." ${ }^{20}$

Indigenous women experience specific vulnerabilities due to the combination of gender, poverty, and ethnicity. ${ }^{21}$ Not only are they at risk of abusive male behavior within their society, but they are also vulnerable to abuse and violence by males from the dominant cultural group. For example, San women are regarded as promiscuous and sexually available so that rape of a San woman may not be considered as sexual abuse. ${ }^{22}$

\section{Multiple Vulnerabilities of Women}

There is a need for a nuanced, contextualized understanding of gender-based vulnerability among population groups as a basis for developing responses that give special protection to the most vulnerable. If the poor are at the bottom of the social ladder, poor women are on the lowest rung. This differentiates the vulnerability of men and women in poverty.

Chronic and simultaneously occurring risks cumulatively weaken protective capacity over time. Furthermore, those risks that cannot be avoided or mitigated because of weak protective capacity have a way of creating other, related risks. For example, the risk of job loss is high in a nonunionized/unregulated labor market (weak protective capacity), which creates a related risk of homelessness. Poor individuals, families, communities, and nations share this type of fragility.

The risk of exploitation in medical research exposes poor people to the related risks of health deprivation. This is because when the poor do not receive their fair share of the benefits of research, that is, when they are deprived of access to 
necessary medicines, they are further deprived of the opportunity or potential for improving their situation, that is, to attain better health. Their poor state of health may put them at risk of (further) exploitative research, if participation is the only way to access the medicines they need.

Our research has demonstrated that access to free healthcare has been a major motivating factor for participants in the Majengo HIV/AIDS study; "I agreed because when I am sick they help me a lot and when my immunity is down they will also help me." 23

Risk and protective capacity are dialectically related, in that risks are heightened by a weak protective capacity, and a weak protective capacity exposes the individual to additional risks. This can be illustrated by contrasting the case of healthy, altruistic women in the developed world who choose to donate ova to research programs to assist their childless peers with those of financially needy women in the developing world who undergo potentially dangerous and invasive procedures for the extraction of thousands of ova, although the potential benefits of this research may not ultimately be available to them. ${ }^{24}$ It is clear here how a weak protective ability (being marginalized and uneducated) increases the risk of exploitation for the poor women.

\section{Theorizing Women's Vulnerability}

As we have shown, although poverty is a key determinant of vulnerability, gender mediates the impact of poverty on risk and protective capacity. Aside from the risks and lack of protective capacity brought about by their poverty, gender creates additional constraints and deprivation for women.

A gendered analysis of vulnerability prompts us to ask who defines women's vulnerability and the risks and harms they face? Standpoint theorists explain that knowledge is always particular and presupposes a social location, or standpoint, that is a characteristic feature of the knower in question and that can be explained (among other factors) by their economic circumstances. Feminist standpoint epistemologists argue that recognition among scholars of the influence of women's social location on their cognition can lead to a more objective assessment and understanding of women's knowledge. ${ }^{25}$ By engaging with women's individual and collective situated knowledge about the risks and harms they face, we can gain insights into the nature of their vulnerabilities that simply cannot be seen "from outside." In the Majengo HIV/AIDS study, women's participation is compromised by the researchers' requirement, in a setting where prostitution is illegal, "that they must accept and acknowledge that they are sex-workers." 26 Meanwhile, the community is well aware of the associated risk of stigmatization from being involved in the study; "they are scared to come, and you see if they come here they are known to have 'that sickness'." 27 Such knowledge will be crucial to women's understanding of their own lives and needs and therefore central to issues around, for example, their participation in research or their position regarding benefit sharing.

However, because there is insufficient recognition of the impact of these gender-based vulnerabilities, there is a failure to address the need for protective mechanisms that specifically engage with women's vulnerabilities. Andanda, for example, advocates operationalizing existing guidance to secure benefit sharing for the Majengo participants. ${ }^{28}$ However, without addressing the gendered nature 
of the vulnerabilities she identifies, this strategy provides only a limited challenge to the existing governance structures that have marginalized the women's concerns. One way to address this is to mainstream gender in the conceptualization of, and research on, vulnerability.

\section{Gender-Based Vulnerability in Benefit Sharing}

\section{Representation of Women's Interests}

Women's participation in political affairs is founded on three considerations: (a) justice, (b) specific interests that only women can represent, and (c) the fact that women's participation can strengthen democratic institutions and processes. ${ }^{29}$ It is common for women to be underrepresented in or excluded from political affairs such as negotiations and decisionmaking about benefit sharing. ${ }^{30}$ Given that participation in negotiation and decisionmaking are tools for protection against exploitation, this implies that women's capacity for protection against exploitation is further weakened.

The question of women representing their own interests is problematic. There are two key issues here: (a) adequacy of representation and (b) women's own consciousness about their specific interests.

Women's representation or participation in decisionmaking is adequate only when they have the political presence to ensure that their participation has had an impact on the decisions made. It is not by numbers alone that representation or participation is to be assessed, particularly when we are dealing with gendered inequity in political decisionmaking. It should also be in terms of women's ability to protect their interests. "The key difference . . . is whether one looks at the composition of parliament to determine its representativeness, or whether one looks at the decisions made.",31

But who should define women's interests and decide whether these have been reflected favorably in the decisions made? The Kani case is illustrative of the complexity of issues of adequacy and interest representation. Here, profits from the commercial development of a product based on the Indian Kani people's traditional use of "Jeevani" are shared with them through a benefit sharing agreement.

In addition to nine elected male members, there are two women on the Executive Committee of the Kerala Kani Samudaya Kshema Trust, which makes decisions about the use of the Trust fund from the benefit sharing arrangement. ${ }^{32}$ In the allocation of the Trust fund relevant to women's needs, some money has been put aside for the daughters of a woman who was killed by an elephant and some for the family of another woman who committed suicide.

This has been cited as evidence both that women participate in decisionmaking and that women's needs are taken care of in the Kani Trust Fund. ${ }^{33}$ We can argue that this reflects thinking that conflates the interests of children with those of their mothers on the assumption that mothers do not have interests distinct from those of their children. This goes against the empirical evidence that women in tribal societies in Kerala have serious health problems independent from those experienced by their children and family. ${ }^{34}$

Why is this so? The explanation could lie in the fact that women in all patriarchal societies often internalize the gendered ideology of their society, both as a result of socialization and because of the continuing power of patriarchal structures in 
society. The basic interpretive frameworks that shape women's conceptual schemes in patriarchal cultures are constructed in and by social, cultural, and political contexts of oppression that shape and delimit capacities. ${ }^{35}$

Efforts by various sectors, especially women themselves, are therefore necessary for building women's agentic capacities. For example, studies in South Africa have shown that women's ability to suggest condom use and discuss $\mathrm{HIV} / \mathrm{AIDS}$ with an intimate partner is positively correlated with education. ${ }^{36}$ The reduction of gender bias in survival in favor of women is also related to women's agency such as literacy, participation in the labor force, and property rights. $^{37}$

Policy responses in this regard should therefore not rest content with "bringing women to the negotiating table" in a simplistic manner, but should ensure that women in general have the capacity and autonomy to represent their own interests. This requires an exploration of alternative ways to strengthen the protective capacities of women. ${ }^{38}$

\section{Toward Strategies to Build Women's Agency}

Strategies that actively engage with people's knowledge and inherent capacities, including their own understandings of the risks they face and the resources and options available to them, could provide valuable lessons toward the development of more inclusive benefit sharing agreements.

One strategy would be to engage with the potential participant group in advance of the benefit sharing negotiation process, so that the group in question could contribute to identifying its own vulnerabilities prior to and independent of the benefit sharing process in order to bring these issues to the negotiations. Likewise, in order to be realistic, potential ways to address these vulnerabilities (including through benefits that could be shared), need to emerge from within the group itself, as well as being suggested by outsiders. It is crucial, however, that this is a process of dialogue. Many of the risks and dangers faced by the potential participants will inevitably be unforeseeable from their perspective, and it is the researchers' responsibility to present and explore these in a way that facilitates both understanding and a meaningful consent process.

\footnotetext{
Giving agency to those to be "studied" as part of an equal partnership means that we bring to the partnership the skills that each of us has and from these devise a research design that emphasizes symmetry in the research endeavor and attention to community concerns surrounding how and when information should be shared. ${ }^{39}$
}

The self-recognition of women as exploited or oppressed, and therefore as vulnerable to particular risks, has historically often been the first step toward their empowered organization in order to resist and change that state of affairs. ${ }^{40}$ Recognition of a group's vulnerability can therefore be a catalyst for its members to act as a group, thus enhancing both their individual and collective agency, provided that the terms on which they are deemed to be vulnerable resonate with their own understandings and are not externally imposed as yet another form of oppression. ${ }^{41}$ Gender-aware partnering and capacity building approaches to 
benefit sharing are clearly most suited to fostering this kind of development, where women can draw on their existing resources as well as learn new skills.

These approaches envision the true democratization of development processes that consider women (or men) as equal and dignified partners, not as objects of aid or assistance. ${ }^{42}$ Engaging with vulnerability in real-life communities is about developing an awareness of the existence of differing material realities and perspectives and should ideally function to open up a space where the group's agenda and definitions of their own vulnerabilities, along with potential solutions to these problems, can emerge.

\section{Notes}

1. Schroeder D, Gefenas E. Vulnerability: Too vague and too broad? Cambridge Quarterly of Healthcare Ethics, this issue, 113-121.

2. Mason A, King EM. Engendering Development Through Gender Equality in Rights, Resources and Voice: A World Bank Policy Research Report, 2001; available at http://goworldbank.org/UGHQ0FEP50 (last accessed 5 June 2008).

3. Lee S. Assessing the Vulnerability of Women Street Traders to HIV/AIDS: A Comparative Analysis of Uganda and South Africa. Durban: Health Economics and HIV/AIDS Research Division (HEARD), University of KwaZulu-Natal; July 2004. For strategies on building women's agentic capacities, see Alvarez-Castillo F, Lucas JC. Fairness and Gender in Benefit Sharing, 2008; available at www.uclan. ac.uk/genbenefit (last accessed 15 December 2008).

4. United Nations Environment Programme. Convention on Biological Diversity, Article 8j, available at http:/ /www.cbd.int/convention/articles.shtml?a $=$ cbd-08, (last accessed 17 June 2008).

5. Alvarez-Castillo F, Feinholz D. Women in developing countries and benefit sharing. Developing World Bioethics 2006;6(3):113-21; UNESCO. International Declaration on Human Genetic Data, 2003; available at http://portal.unesco.org/en/ev.php-URL_ID =17720\&URL_DO=DO_TOPIC\&URL_ SECTION=201.html (last accessed 5 March 2008); The Human Genome Organisation (HUGO) Ethics Committee. Statement on Benefit Sharing, 2000, p. 121; available at www.hugo-international.org/ Statement_on_Benefit_Sharing.htm accessed (last accessed 5 March 2008).

6. See note 3, Alvarez-Castillo, Lucas 2008.

7. See note 5, Alvarez-Castillo, Feinholz 2006:114.

8. Sauer B. Relevance of (Research on) Representation of Women in Politics. Université de Genève. Draft; March 12, 2004.

9. Krug E, Dahlberg L, Mercy J, Zwi A, Lozano A, eds. World Report on Violence and Health. Geneva: World Health Organization; 2002.

10. United Nations Population Fund. Chapter four: The feminization of HIV/AIDS. In: State of the World Population. New York: UNFPA; 2005.

11. See note 10, United Nations Population Fund 2005.

12. Dworkin S, Ehrhardt A. Going beyond "ABC" to include "GEM": Critical reflections on progress in the HIV/ AIDS epidemic. American Journal of Public Health 2007;92:133-7; Chan KY, Reidpath D. "Typhoid Mary" and "HIV Jane:" Responsibility, agency and disease prevention. Reproductive Health Matters 2003;11(22):40-50.

13. Jewkes R, Levin J, Penn-Kekana L. Gender inequalities, intimate partner violence and HIV preventive practices: Findings of a South African cross-sectional study. Social Science and Medicine 2003;56(1):125-34.

14. See note 3, Lee 2004:17.

15. Warren explains patriarchy as the "systematic domination of women by men through institutions, behaviors, and ways of thinking ... which assign higher value, privilege, and power to men ... than to that given to women." Warren KJ. Ecofeminist Philosophy. Oxford: Rowman and Littlefield; 2000:64.

16. For a critical discussion of the literature "revolving around the presumption of primordial gender equality and harmony among the San of southern Africa" see Becker H. The least sexist society? Perspectives on gender, change and violence among southern African San. Journal of Southern African Studies 2003;29(1):5-23.

17. Wessendorf K. Editorial: Indigenous women. Indigenous Affairs 2004;1-2:4-7. 


\section{Gender and Vulnerable Populations in Benefit Sharing}

18. See note 16, Becker 2003:8.

19. Hitchcock R, Johnson M, Haney C. Indigenous women in Botswana: Changing roles in the face of dispossession and modernization. In: Hitchcock R, Vinding D, eds. Indigenous Peoples' Rights in Southern Africa. Copenhagen: IWGIA; 2004.

20. See note 16, Becker 2003:16.

21. See note 17, Wessendorf 2004.

22. Sylvain R. San women today: Inequality and dependency in a post-foraging world. Indigenous Affairs 2004;1-2:8-13.

23. Andanda P, Lucas JC. Majengo HIV/AIDS Research Case: A Report for GenBenefit, 2007; available at www.uclan.ac.uk/genbenefit (last accessed 15 May 2008).

24. Morsigian J. Our Bodies, Ourselves, available at http://www.boston.com/acws/globe/editorial_opinion/ oped/arti (last accessed 10 August 2007).

25. See Harding S. The Science Question in Feminism. Milton Keynes: Open University Press; 1986, especially Chapter 6 "From Feminist Empiricism to Feminist Standpoint Epistemologies," pp. 136-62.

26. See note 23, Andanda and Lucas 2007:18.

27. See note 23, Andanda and Lucas 2007:19.

28. Andanda P. Vulnerability: Sex workers in Nairobi's Majengo slum. Cambridge Quarterly of Healthcare Ethics, this issue, 138-146.

29. United Nations High Commissioner for Human Rights (UNHCHR). Women's Equal Ownership, Access to and Control Over Land and the Equal Rights to Own Property and to Adequate Housing: Commission on Human Rights Resolution 200/49. Geneva: UNHCHR; 2002.

30. See note 5, Alvarez-Castillo, Feinholz 2006.

31. Squires J. Gender in Political Theory. Cambridge/Oxford: Polity Press; 1999:203, quoted in Sauer B. 2004:9 (see note 8). Also see Phillips A. The Politics of Presence. Oxford: Oxford University Press; 1995.

32. Because there were no women candidates for membership of the Committee in the May 2008 election, the Committee appointed two women so that there would be women's representation. Data from a key informant communicated by Sachin Chaturvedi, June 2008.

33. Cited by a woman key informant. The Tropical Botanic Garden \& Research Institute has independently implemented capacity building for women, including an entrepreneurship development program and cooperative society/self-help groups. Data from personal communications with Sachin Chaturvedi, October 2007, June 2008.

34. Maria Rani Centre. Women's Health in Kerala: Issues and Challenges, May 2006; available at http:// www.sakhikerala.org (last accessed 19 October 2007).

35. Dillon RS. Self-respect: Moral, emotional, political. Ethics 1997;107(2):226-49, at 244-5.

36. See note 14, Jewkes, Levin, Pen-Kekana 2003.

37. Dreze J, Sen A. Gender inequality and women's agency. In: Mohanty M, ed. Class, Caste and Gender. New Delhi: Sage; 2004.

38. For a fuller discussion, see Alvarez-Castillo, Lucas 2008.

39. Simonelli J, Comment on Rosenthal, J. Politics, Culture, and Governance in the Development of Prior Informed Consent in Indigenous Communities. Current Anthropology 2006;47-1:119-42 at p. 136.

40. The classic example here is "consciousness raising" in feminist politics. Frye M. The possibility of feminist theory. In: Garry A, Pearsall P, eds. Women, Knowledge and Reality, London: Routledge; 1996:34-47 at pp. 34-5.

41. See, for example, Reclaim the Night: A Women's Annual Global March to Protest Men's Sexual Violence, available at http://www.isis.aust.com/rtn/herstory.htm (last accessed 30 April 2008).

42. A gender-sensitive partnering approach is distinguished by the integration of gender in all aspects of the project. In research, this is exemplified in feminist and participatory action research approaches. For examples, see Banerjee UD, ed. Lessons Learned from Rights-Based Approaches in the Asia Pacific Region. Bangkok: United Nations Development Programme and Office of the UN High Commissioner for Human Rights; 2005. 